\title{
The 26 July 2005 heavy rainfall event over Mumbai: numerical modeling aspects
}

\author{
Sandeep Sahany $\cdot$ V. Venugopal $\cdot$ Ravi S. Nanjundiah
}

Received: 2 May 2010/Accepted: 9 October 2010/Published online: 5 November 2010

(c) The Author(s) 2010. This article is published with open access at Springerlink.com

\begin{abstract}
The performance of the Advanced Regional Prediction System (ARPS) in simulating an extreme rainfall event is evaluated, and subsequently the physical mechanisms leading to its initiation and sustenance are explored. As a case study, the heavy precipitation event that led to $65 \mathrm{~cm}$ of rainfall accumulation in a span of around $6 \mathrm{~h}$ (1430 LT-2030 LT) over Santacruz (Mumbai, India), on 26 July, 2005, is selected. Three sets of numerical experiments have been conducted. The first set of experiments (EXP1) consisted of a four-member ensemble, and was carried out in an idealized mode with a model grid spacing of $1 \mathrm{~km}$. In spite of the idealized framework, signatures of heavy rainfall were seen in two of the ensemble members. The second set (EXP2) consisted of a five-member ensemble, with a four-level one-way nested integration and grid spacing of 54, 18, 6 and $1 \mathrm{~km}$. The model was able to simulate a realistic spatial structure with the 54, 18, and $6 \mathrm{~km}$ grids; however, with the $1 \mathrm{~km}$ grid, the simulations were dominated by the prescribed boundary conditions. The third and final set of experiments (EXP3) consisted of a five-member ensemble, with a four-level one-way nesting and grid spacing of 54, 18, 6, and $2 \mathrm{~km}$. The Scaled Lagged Average Forecasting (SLAF) methodology was employed to
\end{abstract}

\footnotetext{
S. Sahany $(\bowtie)$

Department of Atmospheric and Oceanic Sciences, University of California, Los Angeles, CA 90095, USA

e-mail: sandeep@atmos.ucla.edu

V. Venugopal · R. S. Nanjundiah

Centre for Atmospheric and Oceanic Sciences,

Indian Institute of Science, Bangalore 560012, Karnataka, India

V. Venugopal · R. S. Nanjundiah

Divecha Centre for Climate Change, Indian Institute of Science,

Bangalore 560012, Karnataka, India
}

construct the ensemble members. The model simulations in this case were closer to observations, as compared to EXP2. Specifically, among all experiments, the timing of maximum rainfall, the abrupt increase in rainfall intensities, which was a major feature of this event, and the rainfall intensities simulated in EXP3 (at $6 \mathrm{~km}$ resolution) were closest to observations. Analysis of the physical mechanisms causing the initiation and sustenance of the event reveals some interesting aspects. Deep convection was found to be initiated by mid-tropospheric convergence that extended to lower levels during the later stage. In addition, there was a high negative vertical gradient of equivalent potential temperature suggesting strong atmospheric instability prior to and during the occurrence of the event. Finally, the presence of a conducive vertical wind shear in the lower and mid-troposphere is thought to be one of the major factors influencing the longevity of the event.

\section{Introduction}

During the Indian monsoon season (June through September), especially in the months of July and August, many locations along the west coast of India (towards the windward side of the Western Ghats) receive heavy rainfall. The strong moisture-laden westerlies from the Arabian Sea interact with the topography, causing heavy precipitation over this region. The other important factors leading to such intense rainfall events are the mid-tropospheric cyclones, and organized convection in the tropical convergence zone (e.g., Krishnamurti and Hawkins 1970; Benson and Rao 1987; Ogura and Yoshizaki 1988). In the past, heavy rainfall of the order of $50 \mathrm{~cm} /$ day has been reported at various locations along the Indian west coast (Dhar and Nandargi 1998; Kulkarni et al. 1998). 
Fig. 1 Sea-level pressure (hPa) in contours, overlaid by $850 \mathrm{hPa}$ wind vectors $(\mathrm{m} / \mathrm{s})$, from the FNL analysis valid at $1730 \mathrm{LT}$ (1200 UTC): a 23 July, b 24 July, c 25 July, and d 26 July, 2005

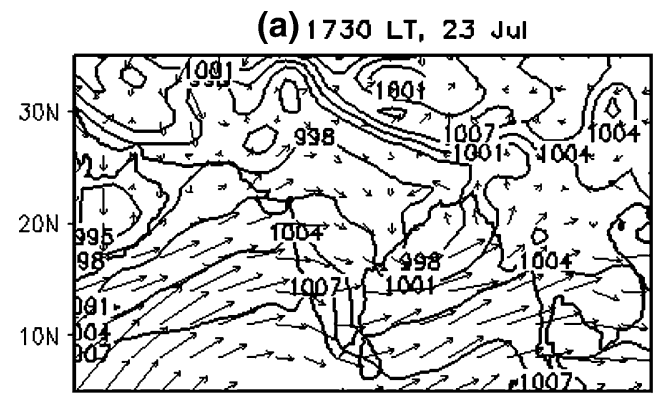

(c) $1730 \mathrm{LT}, 25 \mathrm{Jul}$

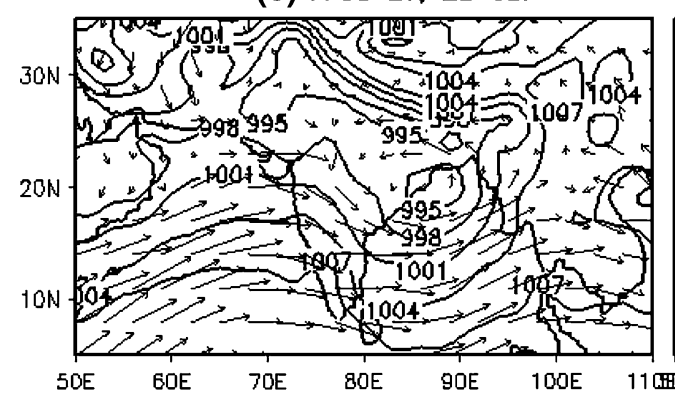

(b) $1730 \mathrm{LT}, 24 \mathrm{Jul}$

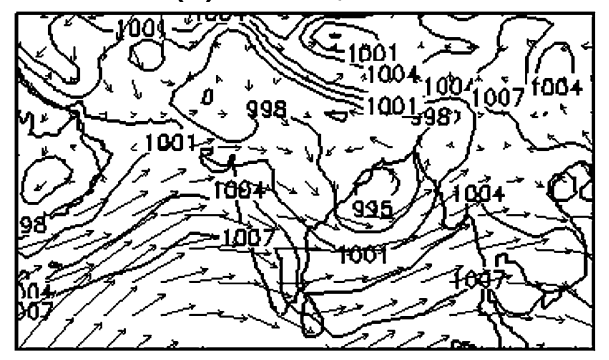

(d) $1730 \mathrm{LT}, 26 \mathrm{Jul}$

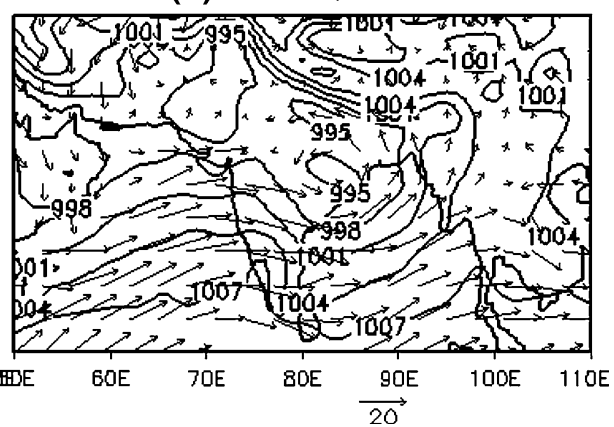

In a previous study, Doswell et al. 1996 emphasized the importance of ingredients-based methodology for flash flood forecasting. They suggested that all flash flood events have some basic ingredients in common, whose presence can be used as potential indicators of heavy precipitation. They reported that heavy precipitation rates involve high values of vertical moisture flux, associated with high vertical velocity and substantial amount of water vapor contained in the ascending air. The other important factor responsible for heavy rainfall rates is the precipitation efficiency, which in turn is a function of the relative humidity of the environment, and several other factors like wind shear. Another relevant study was by Romero et al. 1998, wherein they attempted to simulate three heavy precipitation events in the western Mediterranean region, using a mesoscale model. One of the important conclusions was that the forecasts were reasonably good for two cases in which the synoptic-scale activity was prominent; however, the model prediction was not satisfactory for the third case, which was an isolated convective storm strongly influenced by local effects. Some studies in the past have also highlighted the role of vorticity-stretching in the occurrence of heavy precipitation (e.g., Chakraborty et al. 2006).

The rainfall event over Santacruz (Mumbai, India) on 26-27 July, 2005, was of unprecedented intensity and accumulation in a very short duration. Prior to the occurrence of this event, the monsoon was in its break phase from 19 to 22 July. A low-pressure area formed over the northern Bay of Bengal (off the Gangetic West Bengal and Orissa coast) on 23 July and persisted for a period of
2 days. It became well marked on 25 July, and then started moving inland in the westward direction (see Fig. 1a-d). During the 24-h period of 26-27 July, 2005, Santacruz received a record high rainfall of $94.4 \mathrm{~cm}$. The event was highly localized, which can be gauged from the fact that Colaba in south Mumbai, around $24 \mathrm{~km}$ from Santacruz, received an accumulated rainfall of only $7.3 \mathrm{~cm}$, during the same 24-h period.

Most of the operational numerical models failed to predict this extreme event. In one of the previous studies, Vaidya and Kulkarni (2007) reported that their model failed to simulate the $38.1 \mathrm{~cm}$ of rainfall that occurred during 0900-1200 UTC, 26 July 2005, due to the coarse grid spacing $(40 \mathrm{~km})$. In another modeling study, Deb et al. (2008) investigated the impact of the Tropical Rainfall Measurement Mission (TRMM) Microwave Imager (TMI) sea surface temperature (SST) on the simulation of the heavy rainfall episode over Mumbai, using two different mesoscale models. They found that the intensity of maximum rainfall around Mumbai was significantly improved with TMI SST as the surface boundary condition in both the models. Using the Weather Research and Forecasting (WRF) model, Kumar et al. (2008) reported that an interplay of various factors like the low-pressure area over the Bay, strong moisture convergence, and meridional temperature gradient might have contributed to an event of such magnitude.

A major feature of this event was that around $65 \mathrm{~cm}$ of rainfall was accumulated in a span of $6 \mathrm{~h}$, which amounts to $70 \%$ of the total rainfall being accumulated in just $25 \%$ of the time, hinting at the strong intensities of rainfall that 
might have occurred during the period. In the present work we explore the ability of the Advanced Regional Prediction System (ARPS) in simulating the event, and subsequently investigate some of the important physical mechanisms involved. We start with an idealized model integration, and then conduct further simulations in a realistic framework using two kinds of ensemble techniques, namely, the standard method for ensemble construction (model integrations starting at different times) and the Scaled Lagged Average Forecasting (SLAF) technique. We evaluate the performance of the model, based on three attributes, namely, location, timing and intensity of the simulated rainfall maximum, and then choose the best member from each of the two realistic sets of experiments, and analyze some of the physical aspects of the event.

The following is the structure of the paper: details of the modeling strategy and the data sets used are presented in Sect. 2. In Sect. 3, we present the main results from this work, followed by conclusions in Sect. 4 .

\section{Data and modeling details}

The model used is a non-hydrostatic mesoscale model called the Advanced Regional Prediction System (ARPS), version 5.2.6, developed at the Center for Analysis and Prediction of Storms (CAPS), University of Oklahoma (Xue et al. 2000, 2001). In the present study, three sets of experiments have been carried out with increasing order of complexity. The modeling strategy used for the various numerical experiments conducted is presented in the form of a flowchart in Fig. 2a. The first set of experiments (hereafter referred to as EXP1) was carried out in an idealized framework. The grid spacing used was $1 \mathrm{~km}$, spanning $200 \times 200$ grid points in the horizontal. The physics component consists of soil model, surface physics, boundary layer, radiation, and cloud microphysics (note that the convection scheme is not used here). There are 43 terrain-following vertical levels, stretching from $100 \mathrm{~m}$ near the ground to around $1 \mathrm{~km}$ near $20 \mathrm{~km}$ height (domain
Fig. 2 a Modeling strategy for the three sets of numerical experiments, and $\mathbf{b}$ Ensemble construction using the SLAF methodology (adapted from Kong et al. 2004). See text (Sect. 2) for details

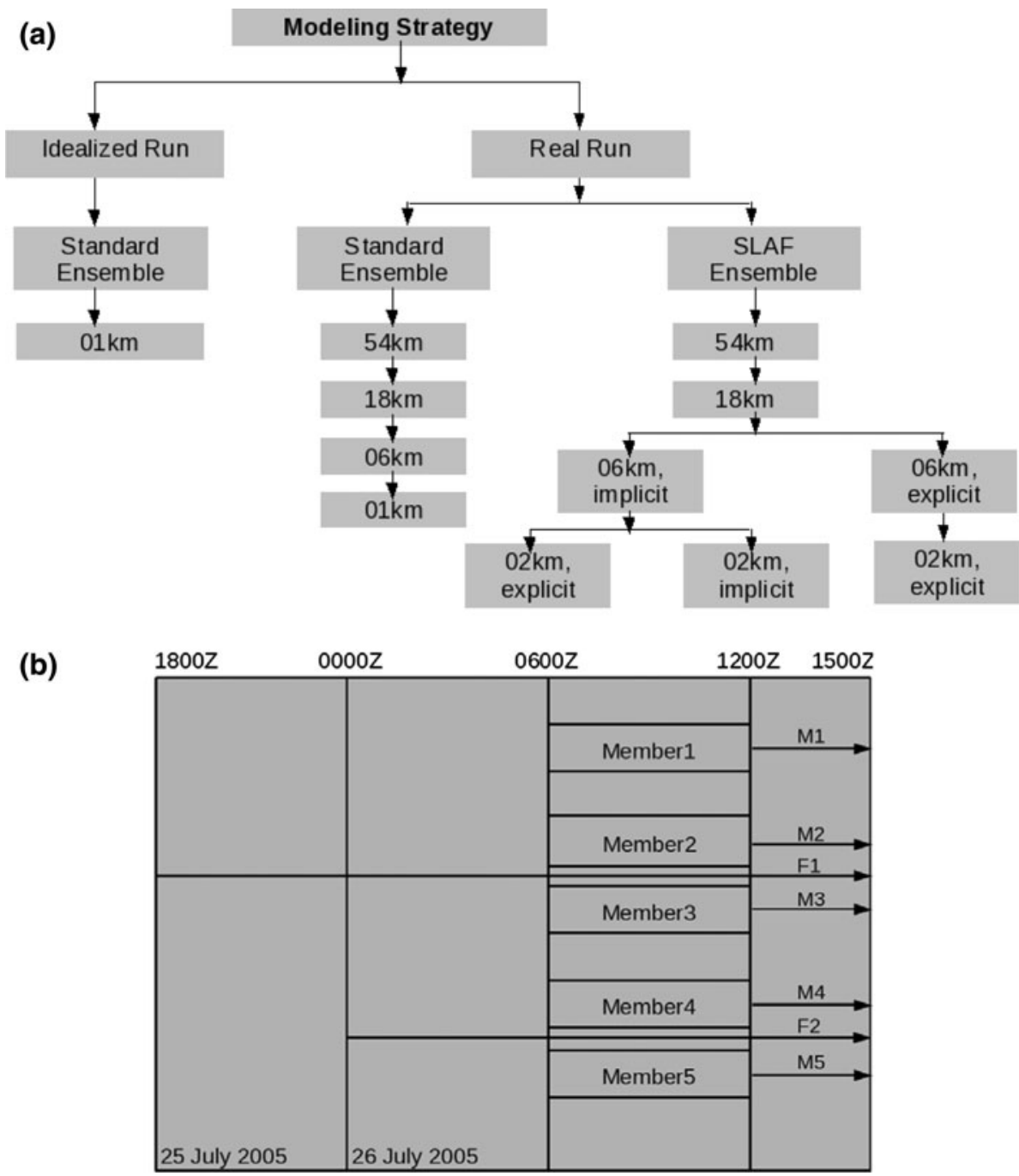


top). Since numerical weather forecasts have a strong dependence on the initial and boundary conditions used, a four-member ensemble is constructed with initial conditions at 12-hourly intervals starting from 1200Z, 24 July 2005 to 0000 Z, 26 July 2005.

In the second set of experiments (hereafter referred to as EXP2), we use a realistic modeling framework, unlike the idealized one used in EXP1, in order to have a more accurate picture of the event. A four-level one-way interactive nesting is used, with grid spacing from the coarsest to the finest as $54,18,06$, and $01 \mathrm{~km}$, respectively, spanning $135 \times 135$ grid points in the horizontal (Fig. 3a). The physics components are the same as that for the idealized run, except that for 54 and $18 \mathrm{~km}$, convective parameterization is used. There are 43 terrain-following vertical levels, stretching from $100 \mathrm{~m}$ near the ground to around $1 \mathrm{~km}$ near the domain top at $20 \mathrm{~km}$. A five-member ensemble is constructed with initial conditions at 6-hourly interval starting from 0600Z, 25 July 2005 to 0600Z,
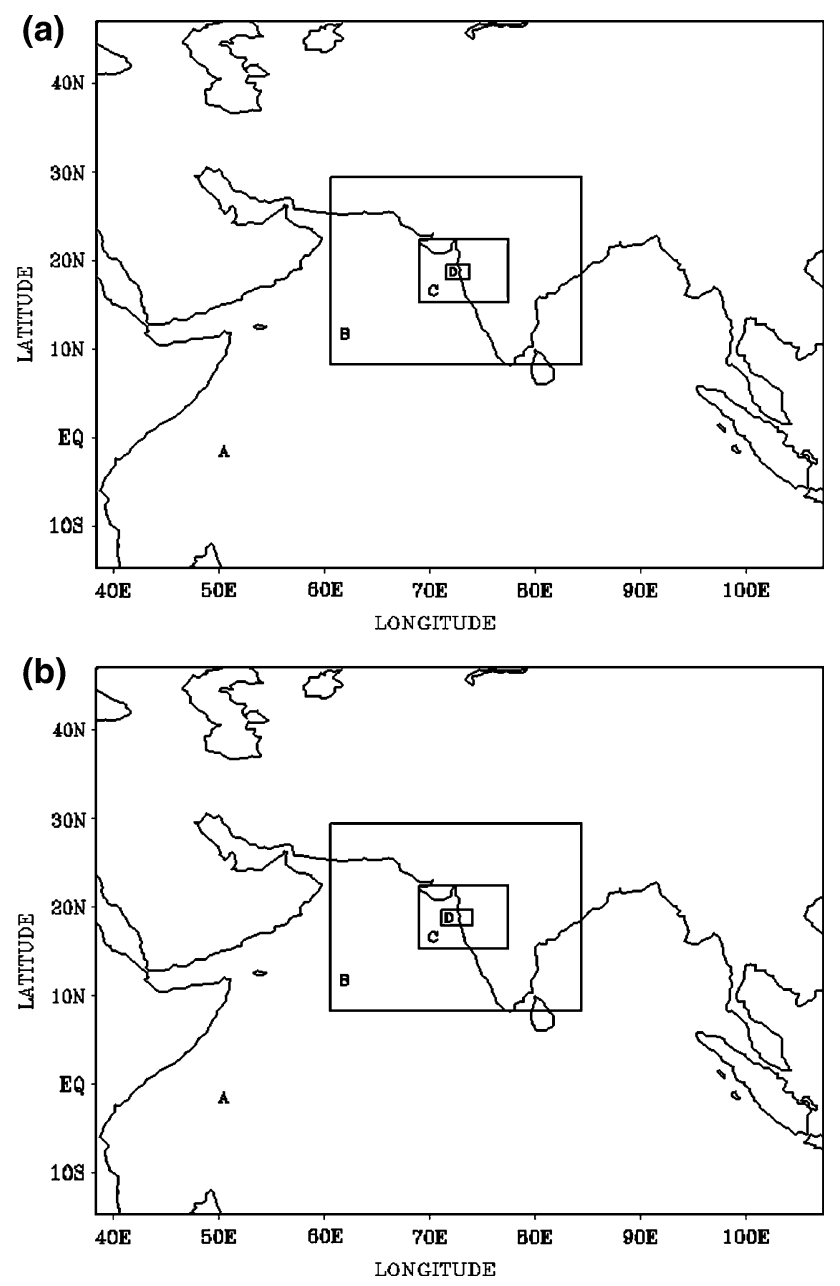

Fig. 3 Model domains for a EXP2, and b EXP3, where ' $A$ ' is for 54 $\mathrm{km}$, ' $B$ ' is for $18 \mathrm{~km}$, ' $C$ ' is for $6 \mathrm{~km}$, and ' $D$ ' is for the $1 \mathrm{~km}$ grid for EXP2, and $2 \mathrm{~km}$ grid for EXP3
26 July 2005. The National Center for Environmental Prediction (NCEP)/National Center for Atmospheric Research (NCAR) Final Analysis (FNL) at $1 \times 1$ degree horizontal resolution is used as the initial and boundary conditions for the coarsest grid of $54 \mathrm{~km}$.

Since the model simulations are known to be affected by the details of the ensemble methodology employed (e.g., Kong et al. 2006), the third set of experiments (hereafter referred to as EXP3) uses a relatively new technique of ensemble construction known as the Scaled Lagged Average Forecasting or SLAF (Kalnay 2003; Kong et al. 2006). The model setup is same as EXP2, except for the construction of ensembles, and the finest horizontal grid spacing being $2 \mathrm{~km}$ (Fig. 3b) instead of $1 \mathrm{~km}$ (this was done since the model simulations with the $1 \mathrm{~km}$ grid in EXP2 were not satisfactory). The five-member ensemble is constructed with initial and boundary conditions generated by perturbing the initial state in accordance with the SLAF (see Fig. 2b). The initial and boundary conditions for the ensemble members were constructed as described below. For the first ensemble member (M1), the initial and boundary conditions are from the NCEP/NCAR FNL data at $0600 \mathrm{Z} 26 \mathrm{July}, 2005$. To generate the initial and boundary conditions for the second and third ensemble members (M2 and M3, respectively), NCEP/NCAR FNL data at $1800 \mathrm{Z} 25 \mathrm{July}, 2005$ was used to produce forecasts valid at $1500 \mathrm{Z} 26$ July, 2005, by integrating the model for a period of $21 \mathrm{~h}$. Scaled differences between the model forecast (F1, see Fig. 2b) and M1 were computed and then added to and subtracted from the analysis data to generate the initial and boundary conditions for the members M2 and M3, respectively. Similarly, forecasts valid at $1500 \mathrm{Z}$ 26 July, 2005 were generated by integrating the model for a period of $15 \mathrm{~h}$, starting from the NCEP/NCAR FNL data at 0000Z 26 July, 2005, and scaled differences between the model forecast (F2, see Fig. 2b) and M1 were used to generate the initial and boundary conditions for M4 and M5. Finally, for the $2 \mathrm{~km}$ model, the following three experiments were performed in order to investigate the role of cumulus scheme at fine spatial resolutions:

- $2 \mathrm{~km}$ : explicit convection; initial and boundary conditions from $6 \mathrm{~km}$ explicit convection.

- $2 \mathrm{~km}$ : explicit convection; initial and boundary conditions from $6 \mathrm{~km}$ implicit convection.

- $2 \mathrm{~km}$ : implicit convection; initial and boundary conditions from $6 \mathrm{~km}$ implicit convection.

The spatial distribution of rainfall accumulation simulated by the model was compared with the TRMM 3B42 data set (3-hourly, 0.25 degree horizontal resolution; see Adler et al. 2000; Huffman et al. 2007), whereas for the comparison of rainfall timing and intensity, ground-based observations from the India Meteorological Department 
Fig. 4 6-hourly rainfall accumulations (mm) during 0900Z-1500Z (1430-2030, local time) 26 July 2005 , as observed by the TRMM satellite

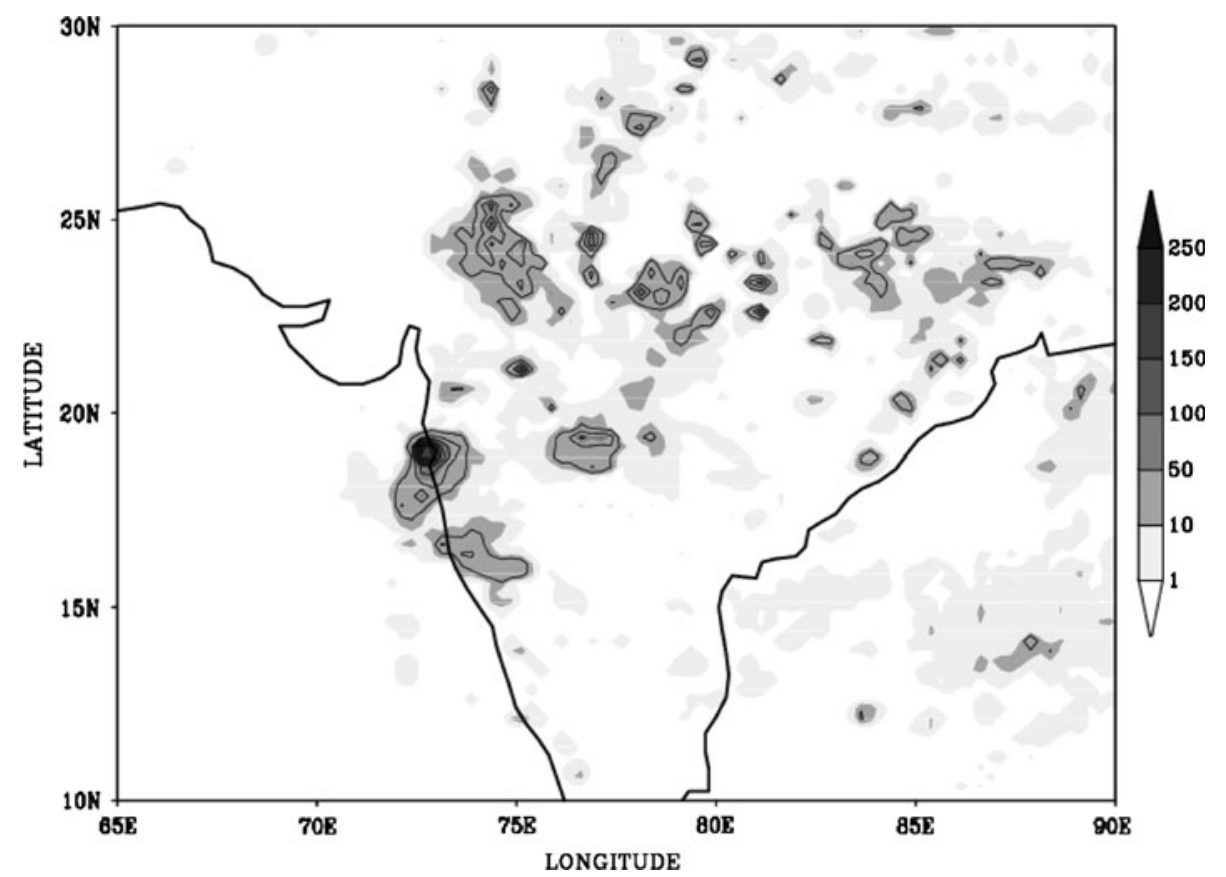

(IMD) were used. Figure 4 shows the TRMM-observed spatial distribution of the 6-hourly accumulations of rainfall during 0900Z-1500Z (1430-2030 local time) 26 July 2005 , over the region of interest. The localized heavy rainfall in and around Santacruz $(19.11 \mathrm{~N}, 72.85 \mathrm{E})$ can be clearly seen from the figure. The other important thing to note is that the rainfall accumulation as seen from TRMM is significantly less than that reported from the rain gauge data; for this reason, we preferred to use the TRMM data only for comparison of the simulated spatial pattern of rainfall, whereas, for the comparison of timing and intensity the IMD rain gauge data over Santacruz was used.

\section{Results and discussion}

\subsection{Idealized set of experiments}

Figure 5 shows the rainfall accumulation for the period 1430-2030 LT, 26 July 2005 from the idealized experiments. It can be clearly seen that there are signatures of heavy rainfall, even though the initial conditions were horizontally homogeneous. Three out of four ensemble members of EXP1 show heavy precipitation, but there are significant differences in the spatial structure and magnitude of rainfall simulated by the individual members (see Fig. 5a-c). The simulated maximum 6-hourly rainfall accumulation for the period is approximately $36 \mathrm{~cm}$, as opposed to the observed value of $65 \mathrm{~cm}$. It can also be noticed from the figure (Fig. 5a, c) that the spatial pattern of the 6-hourly accumulation is very heterogeneous, thus suggesting high spatial variability of the event, which was evident from satellite observations (Fig. 4).

\subsection{Experiments using the standard ensemble technique}

In the second set of experiments (see Sect. 2), NCEP/ NCAR FNL data was used as initial and boundary conditions for the model (as opposed to the idealized conditions used above). Figure 6 shows the spatial pattern of the model-simulated 6-hourly rainfall accumulation, with a horizontal grid spacing of $54 \mathrm{~km}$. It can be seen that all the ensemble members of EXP2 simulate localized heavy rainfall, with varying magnitudes. The simulated maximum rainfall accumulation for the $6 \mathrm{~h}$ period is around $12 \mathrm{~cm}$, which can be primarily attributed to the fact that the event was highly localized, and the grid spacing of $54 \mathrm{~km}$ is too coarse when compared to the scale of the event.

Analysis of the $18 \mathrm{~km}$ model output (figure not shown) shows that the maximum 6-hourly accumulation is around $40 \mathrm{~cm}$, which is closer to the observed value of $65 \mathrm{~cm}$ as compared to the 54-km simulation. Four out of five ensemble members show heavy localized precipitation, but the simulated location has a spatial shift in all of them. At the next finer resolution, i.e., $6 \mathrm{~km}$, there is an increase in the magnitude of the maximum 6-hourly rainfall accumulation. It can be seen from Fig. 7 that the maximum accumulation is $\sim 150 \mathrm{~cm}$, which is substantially higher than the observed value of $65 \mathrm{~cm}$. It is possible that the response of the model physics to the prevailing atmospheric conditions is stronger than that observed in nature, 
Fig. 5 6-hourly rainfall accumulations $(\mathrm{mm})$ produced from the idealized run with $1 \mathrm{~km}$ grid spacing, initialized by the sounding data of Santacruz at a $1200 \mathrm{Z} 24 \mathrm{July} ; \mathbf{b} 0000 \mathrm{Z} 25$ July; c $1200 Z 25$ July; and d 0000Z 26 July, 2005 (a)

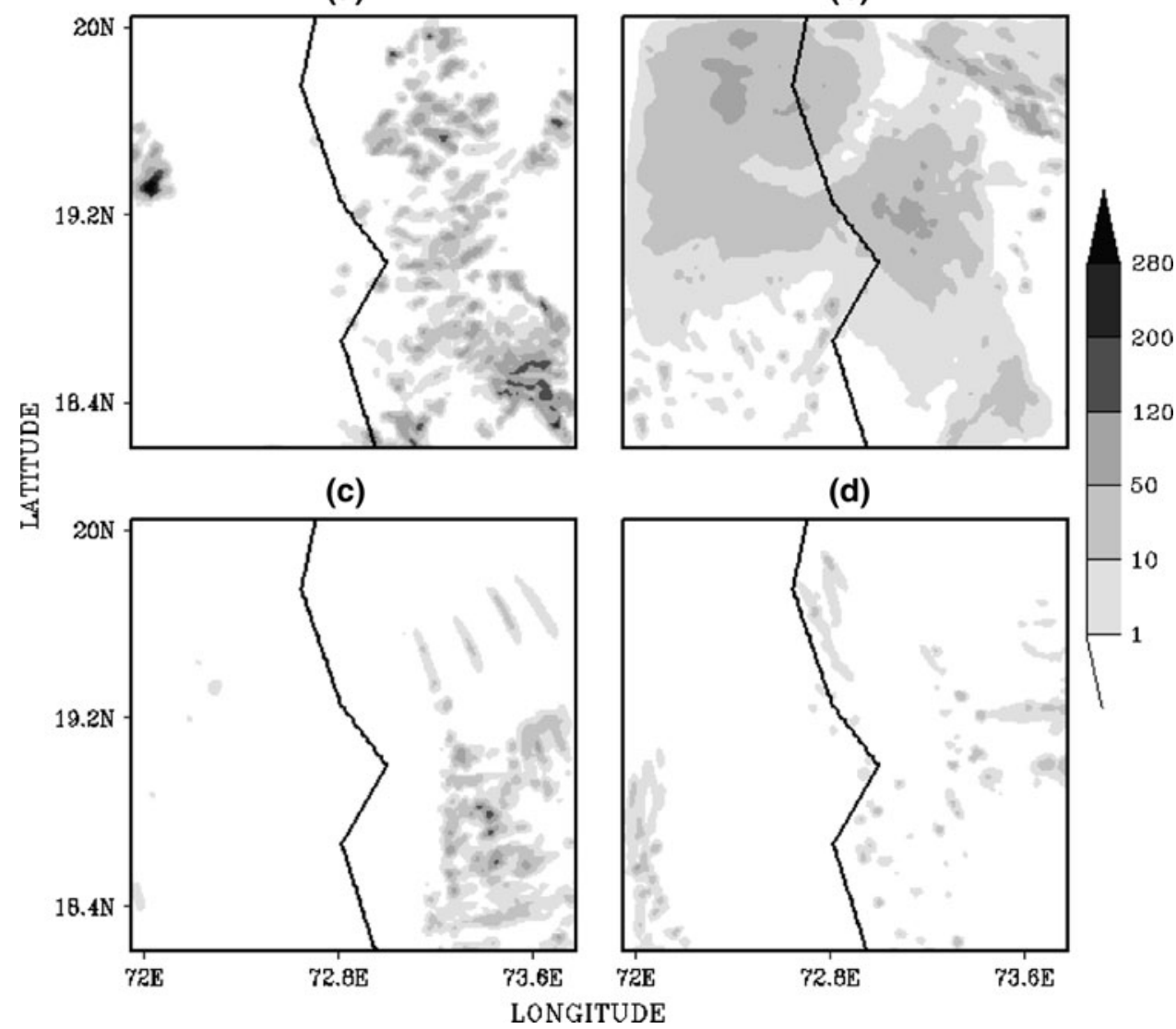

(a)

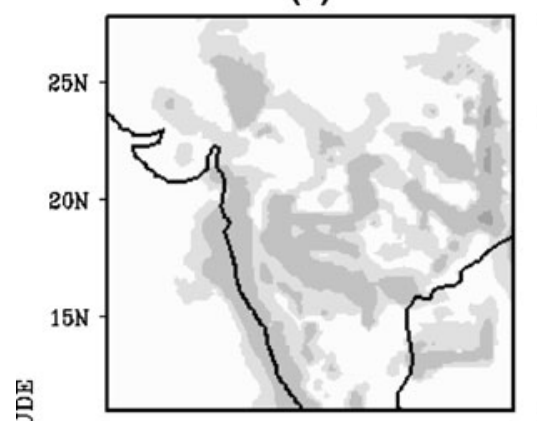

(d)

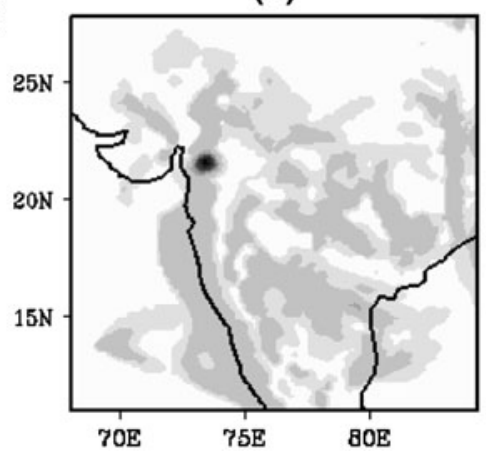

(b)

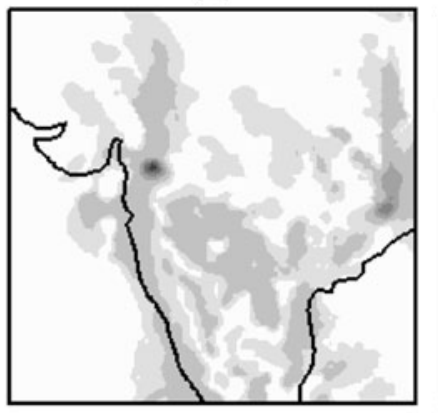

(e)

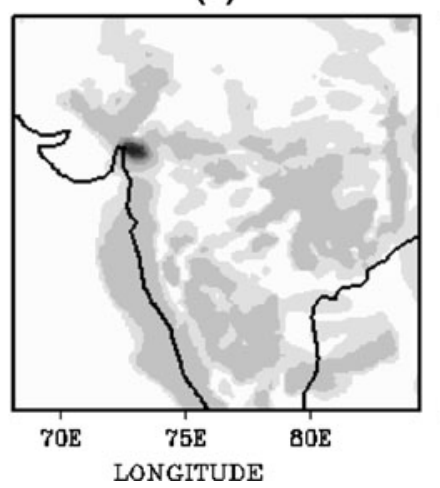

(c)
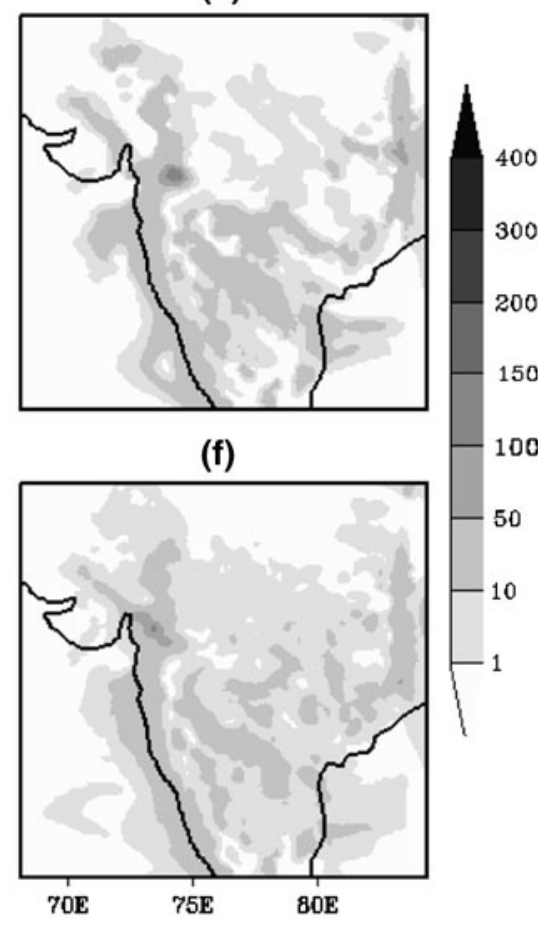

Fig. 6 6-hourly rainfall accumulations ( $\mathrm{mm}$ ) produced from the model simulations with $54 \mathrm{~km}$ grid spacing, initialized by the NCEP/ NCAR FNL data at a 0600Z 25 July (M1); b 1200Z 25 July (M2); c 1800Z 25 July (M3); d 0000Z 26 July (M4); and e 0600Z 26 July, 2005 (M5); f ensemble mean 
(a)

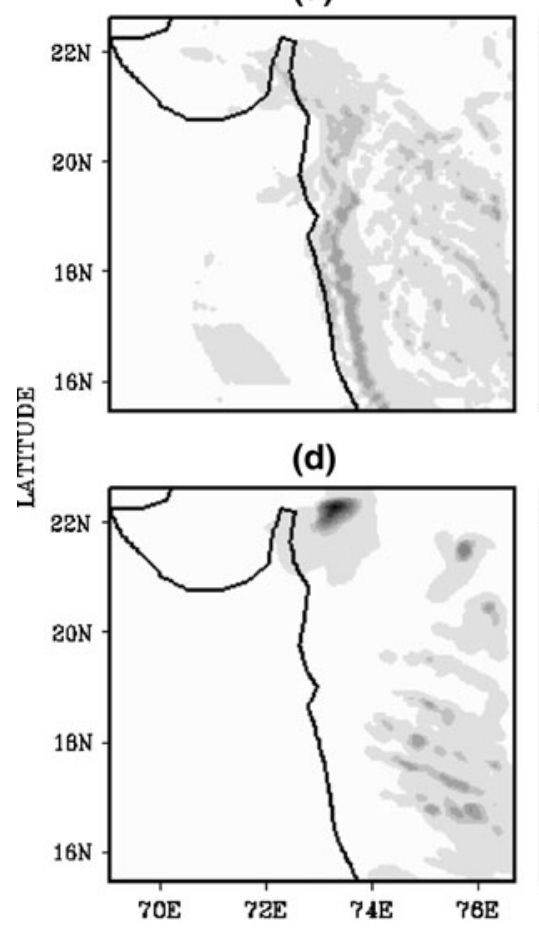

(b)

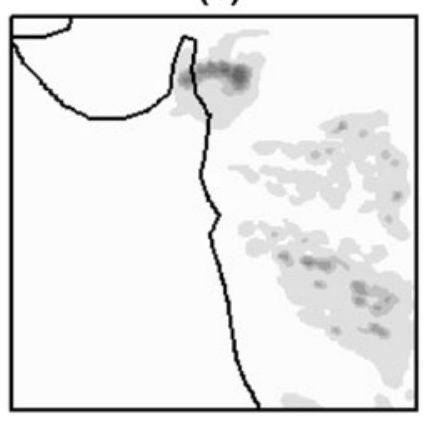

(e)

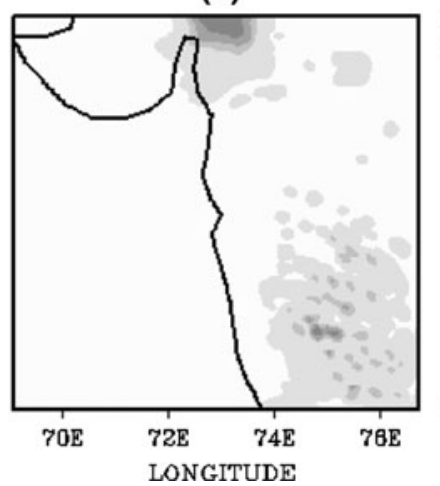

(c)

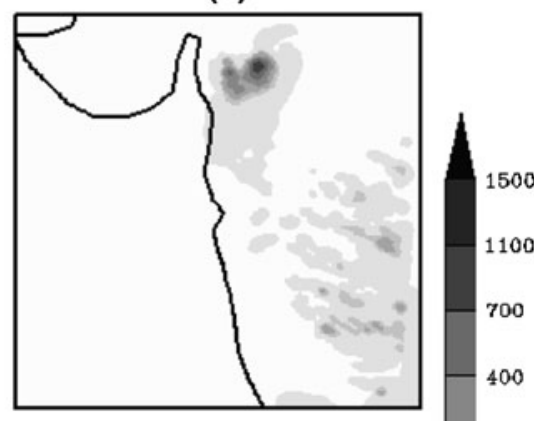

200

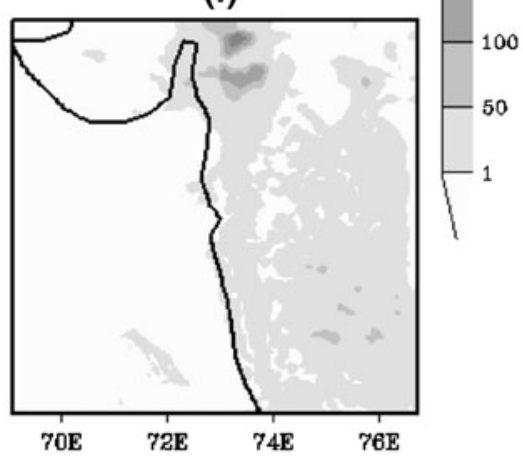

Fig. 7 Same as Fig. 6, but with $6 \mathrm{~km}$ grid spacing. The initial and boundary conditions are from the corresponding $18 \mathrm{~km}$ model output

thus leading to higher rainfall. It should be noted here that this simulation at $6 \mathrm{~km}$ was carried out in an explicit mode (convection-allowing), and hence all the rainfall is in fact grid-scale (produced by the microphysics parameterization). Next we analyze the model simulations with $1 \mathrm{~km}$ grid spacing. This simulation was also carried out in a convection-allowing mode. It was seen that most of the rainfall occurs along the eastern boundary of the model domain (figure not shown), which is probably due to the effect of the boundary conditions prescribed from the $6 \mathrm{~km}$ model. Since the model simulations with $6 \mathrm{~km}$ grid spacing were found to be closer to the observations as compared to those with $1 \mathrm{~km}$ grid spacing, the former was considered for further analysis. Figure 8 shows a comparison of the time series of hourly accumulations over the location of maximum rainfall simulated by the $6 \mathrm{~km}$ model with the observed hourly accumulation (Jenamani et al. 2006). It can be seen from the figure that two of the ensemble members, namely, M3 (Fig. 7c) and M4 (Fig. 7d), are close to observations, as per the timing of maximum intensity. The maximum rainfall intensity as simulated by the model is found to occur at 1530 local time for M3, and 1630 local time for M4, as compared to the observed rainfall peak at 1530 local time. The other parameter used for the evaluation of model performance is the peak rainfall intensity. It can be noticed from Fig. 8 that the peak intensity simulated by the model spans a wide range from

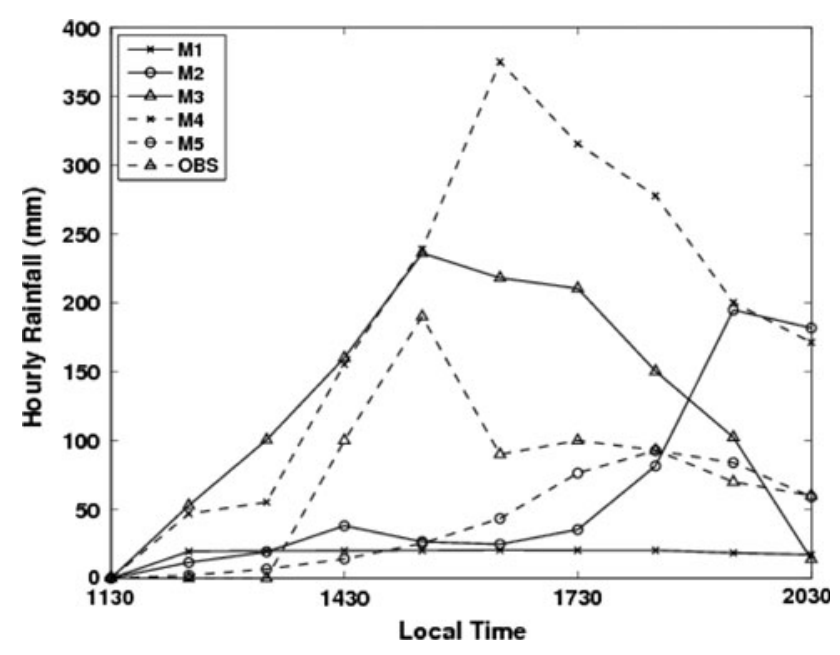

Fig. 8 Time series of hourly rainfall accumulations (mm) over the location of maximum rainfall, from the model simulations (at $6 \mathrm{~km}$ grid spacing) using the standard ensemble technique

around $20 \mathrm{~mm} / \mathrm{h}$ (M1; Fig. 7a) to $370 \mathrm{~mm} / \mathrm{h}$ (M4; Fig. 7d), as compared to the observed value of $190 \mathrm{~mm} / \mathrm{h}$.

\subsection{Experiments using the SLAF technique}

In order to explore the impact of the ensemble methodology, we conducted another set of experiments using a relatively new technique called the Scaled Lagged Average 
(a)

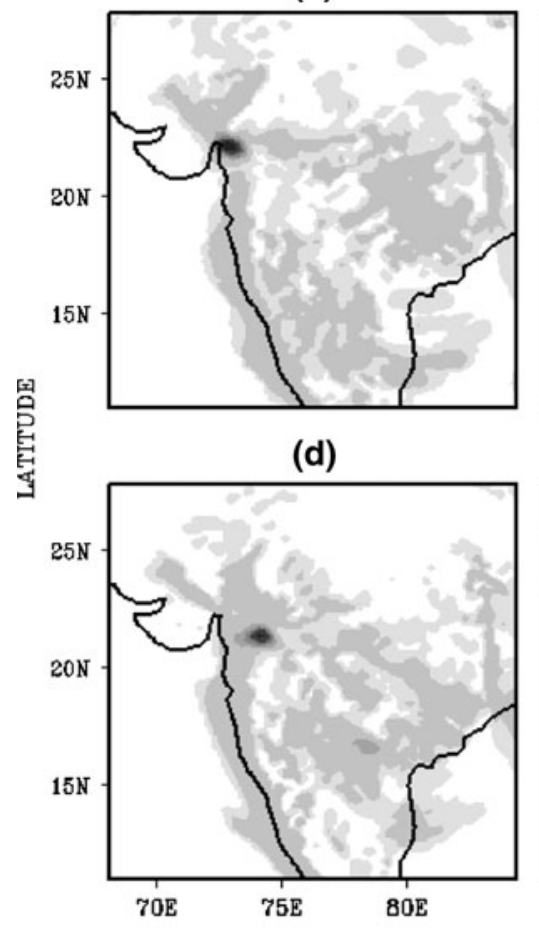

(b)

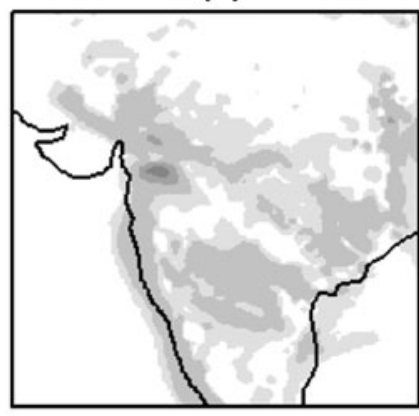

(e)

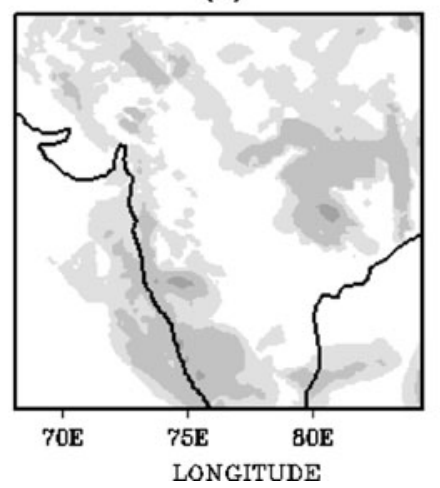

(c)

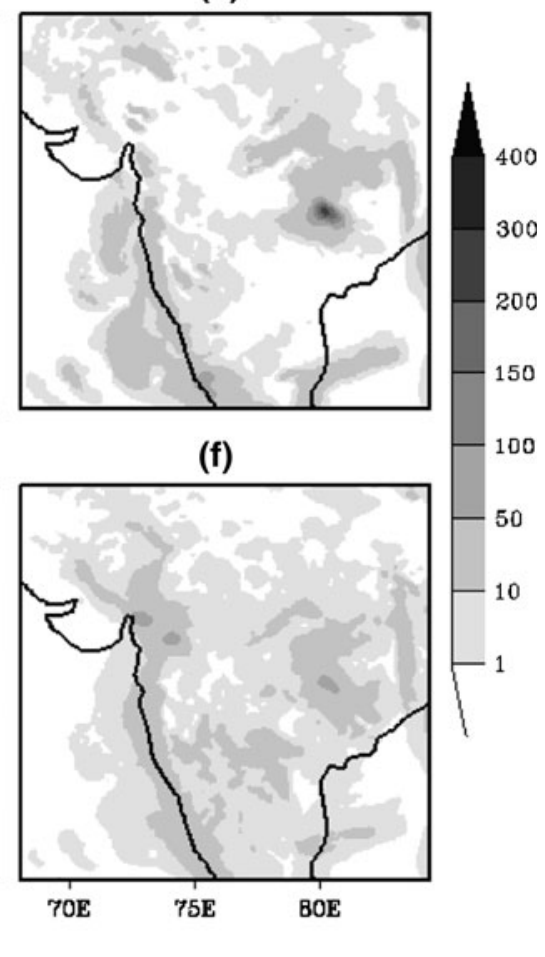

Fig. 9 6-hourly rainfall accumulations $(\mathrm{mm})$ produced from the model simulations with $54 \mathrm{~km}$ grid spacing, initialized by the SLAF technique in the following way: a no perturbation (M1); b, c positive/ negative perturbation to the forecast starting at 1800Z 25 July (M2/ M3); and d, e positive/negative perturbation to the forecast starting at 0000Z 26 July, 2005 (M4/M5); f ensemble mean
Forecasting (SLAF) (see also Sect. 2 and Fig. 2 for the construction of ensemble). Figure 9 shows the spatial distribution of the 6-hourly rainfall accumulation simulated by the $54 \mathrm{~km}$ model. It can be seen that all the members of EXP3 simulate localized heavy rainfall with varying magnitudes and spatial structures, as was also observed in EXP2. The maximum value for the model-simulated 6-hourly rainfall accumulation is around $13 \mathrm{~cm}$, as compared to the observed value of $65 \mathrm{~cm}$. As in EXP2, this could be due to the coarser resolution of the model, in relation to the spatial scale of the event. From the $18 \mathrm{~km}$ model output it is seen (figure not shown) that three out of five ensemble members are able to simulate the localized heavy rainfall. The maximum rainfall accumulation is around $40 \mathrm{~cm}$ as compared to the observed value of $65 \mathrm{~cm}$.

Next we analyze the output from the $6 \mathrm{~km}$ simulation. In this case two experiments were conducted, one with explicit convection, and the other with implicit convection (using a cumulus scheme). Previous studies suggest that rainfall simulation is sensitive to the spatial and temporal resolution of the model (e.g., Weisman et al. 1997, Mishra et al. 2008). With the current state of knowledge, it is still not clear what spatial resolution is necessary for explicit simulation of convection. For example, Weisman et al. (1997) suggested that a horizontal mesh size of $4 \mathrm{~km}$ is sufficient to reproduce much of the structure and evolution of well-organized squall-line type convective systems. In cases where the organization is weak, i.e., with smaller spatial scales of convection, finer resolutions are needed for the explicit simulation of convection. For example, Droegemeier (1994) found that grid spacing of $500 \mathrm{~m}$ or less may be needed to properly resolve the detailed cellularscale features within convective systems. Figure 10 shows 6-hourly rainfall accumulations simulated with the $6 \mathrm{~km}$ grid spacing using explicit convection. It can be seen that four (Fig. 10a-d) out of five ensemble members (except M5; Fig. 10e) show 6-hourly accumulations of around $60 \mathrm{~cm}$ over the region of maximum rainfall, as compared to the observed value of $65 \mathrm{~cm}$. Also notable are spatial shifts in the location of maximum rainfall, which probably cascade down from the $18 \mathrm{~km}$ model. Figure 11 shows the spatial distribution of 6-hourly rainfall accumulations using the Kain-Fritsch (KF) cumulus scheme for the $6 \mathrm{~km}$ model. It can be seen from the figure that similar to the previous case (no cumulus scheme) the 6-hourly accumulations of around $60 \mathrm{~cm}$ are produced over the region of maximum rainfall. The primary difference between them is that the spatial distribution of simulated rainfall using the KF scheme is more widespread over the west coast of India (parallel to the Western Ghats) and extends into the 
(a)

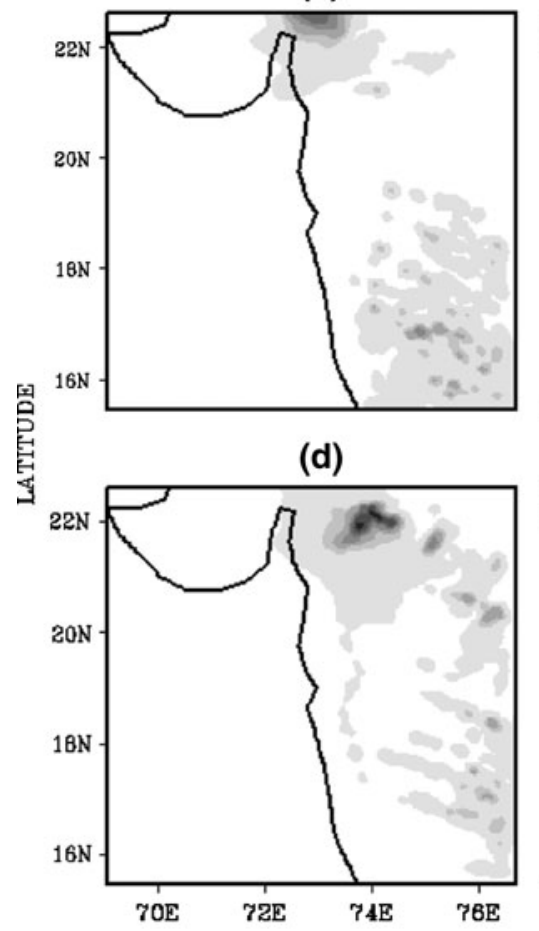

(b)

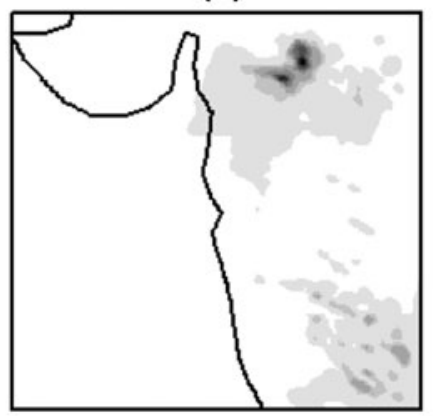

(e)

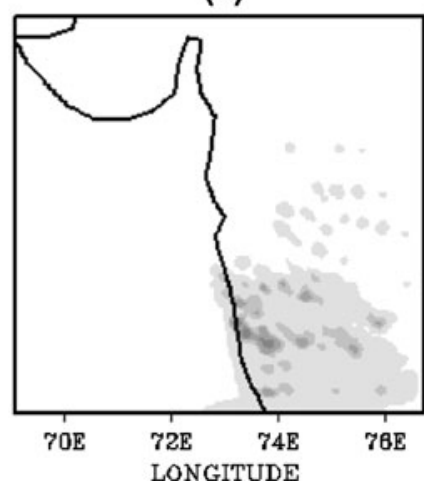

(c)

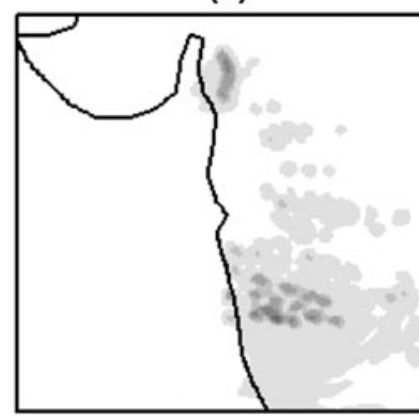

(f)

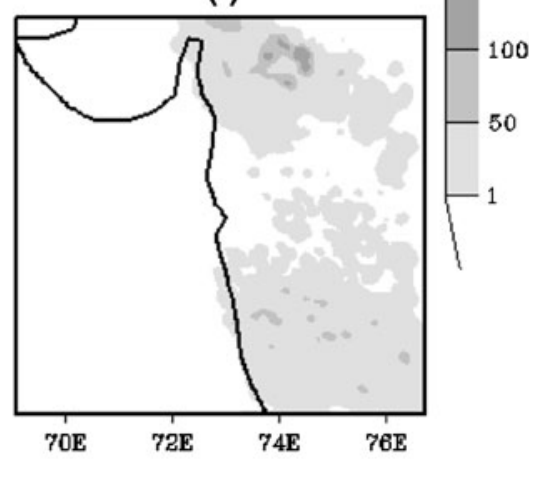

Fig. 10 Same as Fig. 9, but with $6 \mathrm{~km}$ grid spacing and explicit convection. The initial and boundary conditions are from the corresponding $18 \mathrm{~km}$ model output

(a)
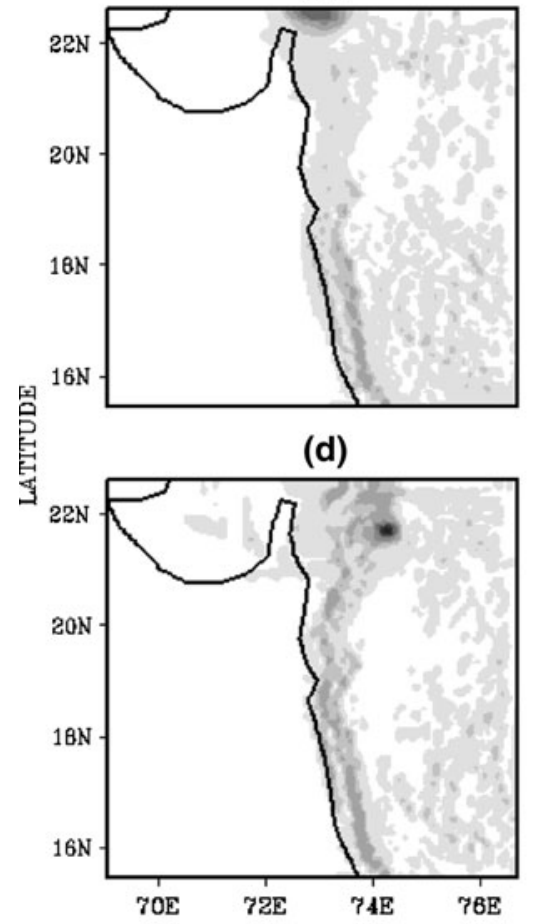

(b)

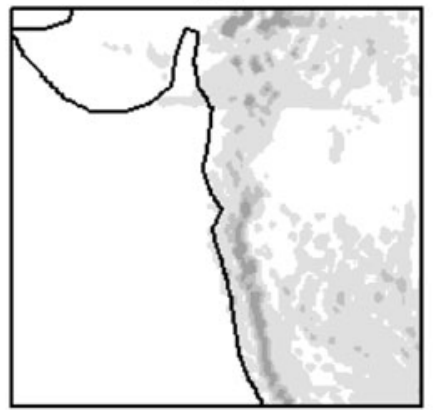

(e)

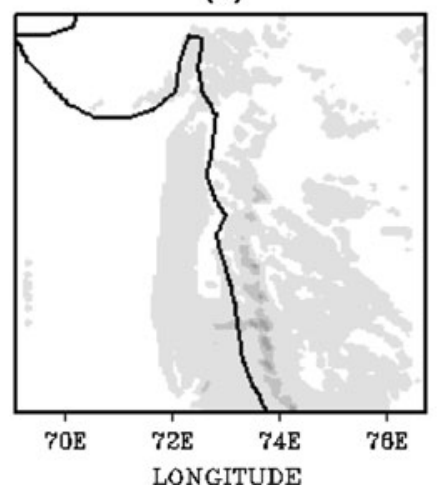

(c)

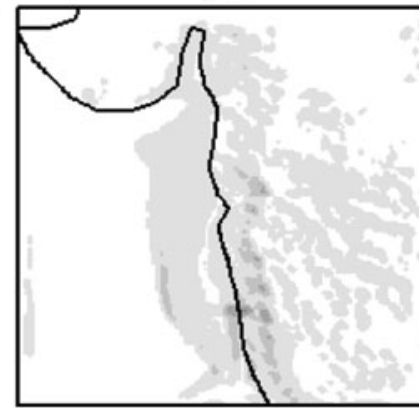

(f)

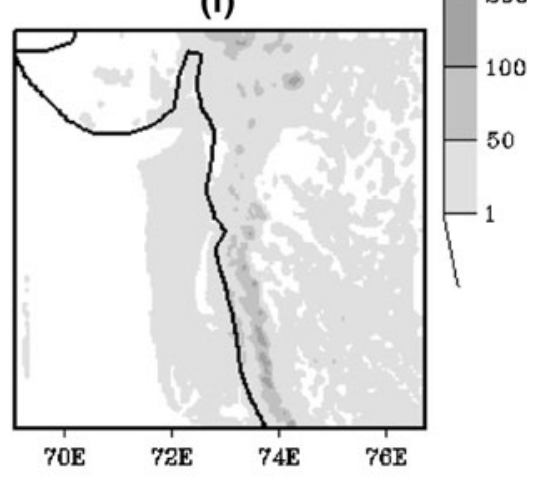

Fig. 11 Same as Fig. 10, but using implicit convection (Kain-Fritsch cumulus scheme). The initial and boundary conditions are from the corresponding $18 \mathrm{~km}$ model output 
Arabian Sea (see Fig. 11c, e, corresponding to M3 and M5, respectively).

Finally, we analyze the model output using the $2 \mathrm{~km}$ grid spacing. It is to be noted that a grid spacing of $2 \mathrm{~km}$ was chosen as opposed to $1 \mathrm{~km}$ (finest grid for EXP2) because at $1 \mathrm{~km}$ the model was unable to simulate the spatial structure of the event, probably due to the strong influence of the boundary conditions obtained from the $6 \mathrm{~km}$ model. The two model simulations with explicit convection show that the rainfall follows the topography of the Western Ghats mountain range and there is no localized heavy rainfall around the region of interest (figure not shown). For the third set with the $2 \mathrm{~km}$ grid spacing, it was seen that the use of the cumulus scheme leads to a smearing of rainfall to other locations (figure not shown). This suggests that even with a $2 \mathrm{~km}$ grid spacing the model was not able to produce a realistic spatial distribution of rainfall accumulation. It is to be noted here that the inability of the model to produce a satisfactory spatial structure at higher resolutions may be specific to this event, and hence should not be treated as a generic conclusion.

Given that the $6 \mathrm{~km}$ model appears to produce the "best" simulation, we compare the rainfall time series over the location of maximum accumulation with the groundbased observations (Jenamani et al. 2006). It can be seen from Fig. 12 that there is a spread in the peak timing among the ensemble members. The hour of maximum rainfall accumulation as simulated by the model, varies from 1530 to 1930 local time, as compared to the observed occurrence at 1530 local time. The abrupt increase in rainfall intensities, as can be seen in the observations, is very well captured by three of the ensemble members, namely, M2, M3, and M5 (Fig. 10b, c, e). It can also be seen from Fig. 12 that the model-simulated hourly rainfall

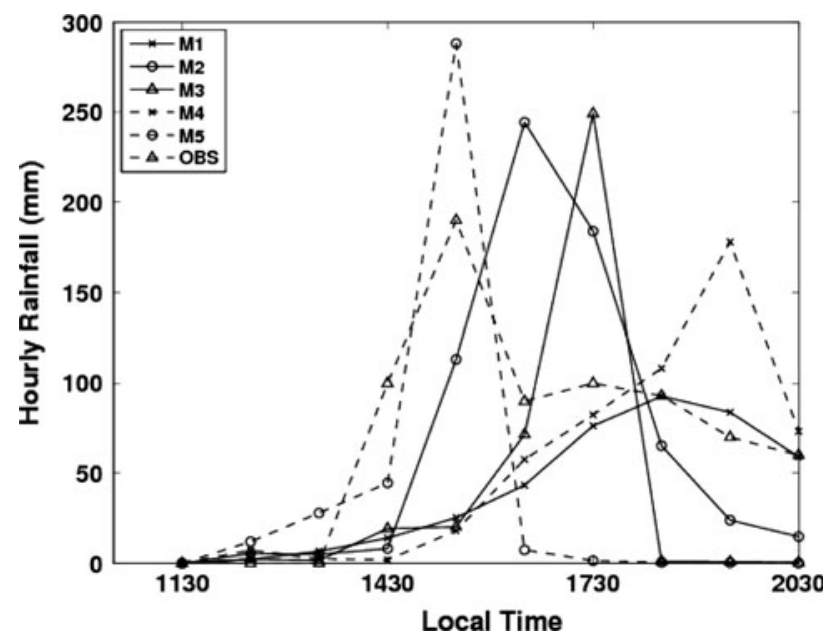

Fig. 12 Time series of hourly rainfall accumulations ( $\mathrm{mm})$ over the location of maximum rainfall produced by the model simulations (at $6 \mathrm{~km}$ grid spacing) using the SLAF technique accumulations vary from 100 to $280 \mathrm{~mm}$, as opposed to the observed value of $190 \mathrm{~mm}$. In order to provide a more comprehensive assessment of the model simulations we perform an analysis of the circulation and thermodynamic attributes between the "best" member of the two sets of ensembles (EXP2 and EXP3).

\subsection{Analysis of the circulation and thermodynamic} features

We first choose the "best" member from the two ensembles based on the spatial distribution of rainfall and the timing of the maximum intensity. Based on these criteria, M3 from EXP2 (Fig. 7c, Fig. 8) and M2 from EXP3 (Fig. 10b, Fig. 12) were chosen for further analysis.

Figure 13 shows a comparison of the circulation pattern simulated by the model at the $54 \mathrm{~km}$ grid spacing, with those obtained from FNL (Fig. 13a1-a3), at different vertical levels. Since the coarsest model resolution used in this study is $54 \mathrm{~km}$, this was chosen for comparison with the analysis data, which has a spatial resolution of $1 \times 1$ degree. It can be seen from the figure that around $850 \mathrm{hPa}$, there is a south-eastward shift of the cyclonic circulation over the east coast of India, in both model simulations (Fig. 13b1-b3; c1-c3). Even at $500 \mathrm{hPa}$, signatures of this spatial shift exist; however, at $200 \mathrm{hPa}$, the circulation pattern in both simulations is found to have a good agreement with the analysis.

Figure 14 shows the time-height section of the divergence pattern over the region of maximum rainfall for the two cases. Both simulations suggest a strong convergence, which initiates at the mid-troposphere $(\sim 8 \mathrm{~km})$ and gradually propagates to the lower altitudes. Thus, it can be concluded that the initiation of convection was due to the mid-tropospheric convergence, which, in later stages, led to strong convergence at the lower levels as well. Analysis of the time-height sections of vertical velocities suggests strong convergence in the lower and mid-troposphere accompanied by strong divergence aloft (Fig. 15). In both cases, vertical velocities are found to peak at a height of around $12-14 \mathrm{~km}$ and above this level the vertical motion starts decelerating, possibly due to the negative buoyancy at those levels. It is interesting to note from the figure that the abrupt nature of the event was very well simulated by the SLAF member (bottom panel in Fig. 15).

A strong wind convergence alone is not sufficient to generate moist deep convection, unless there is sufficient moisture in the atmosphere, especially in the lower and mid-troposphere. In order to investigate the role of moisture, we further analyze the evolution of specific humidity over the region of maximum simulated rainfall. It is evident from Fig. 16 that a large amount of moisture was pumped into the higher altitudes over the region, prior to 


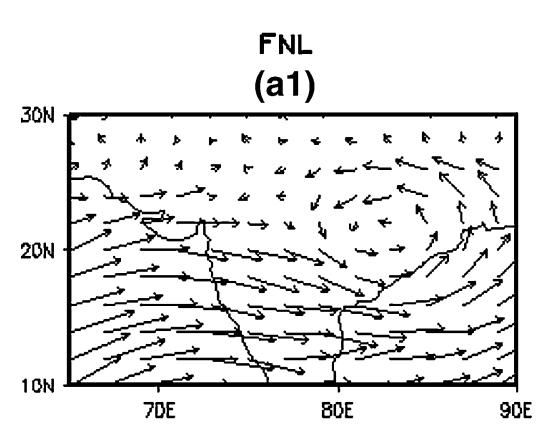

(a2)

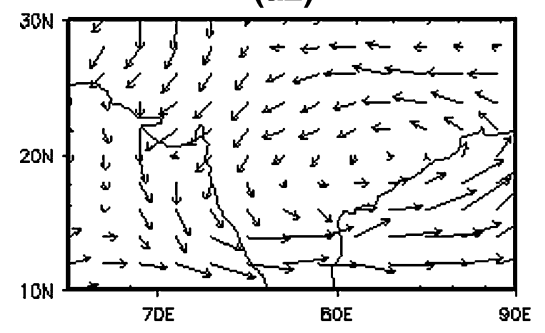

(a3)

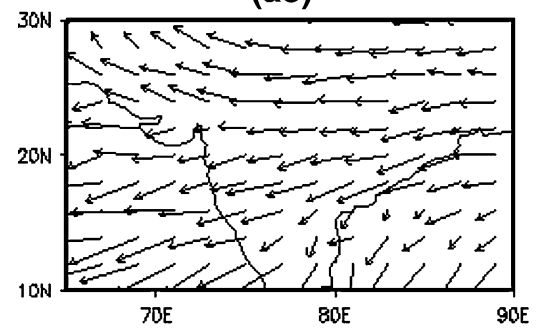

$\operatorname{ExP2}(M 3)$

(b1)

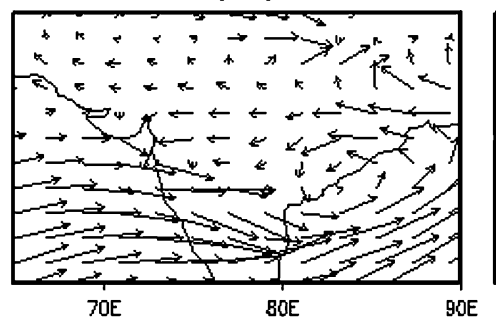

(b2)

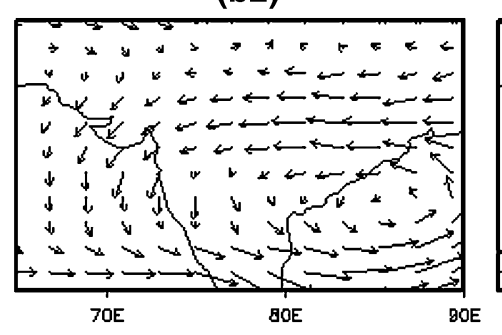

(b3)

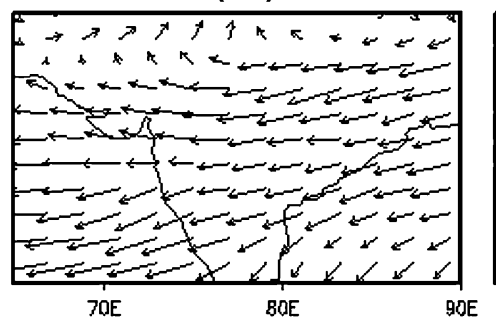

$\operatorname{EXP3}(M 2)$

(c1)

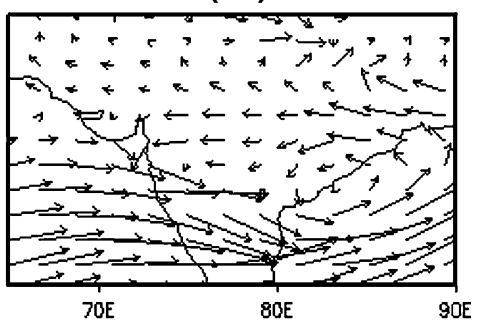

(c2)

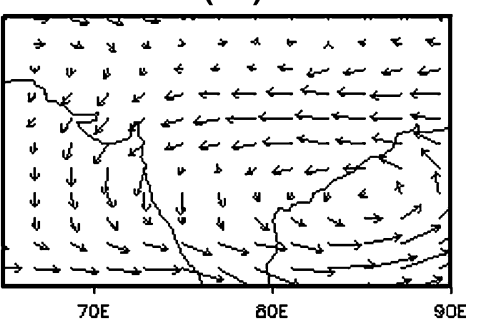

(c3)

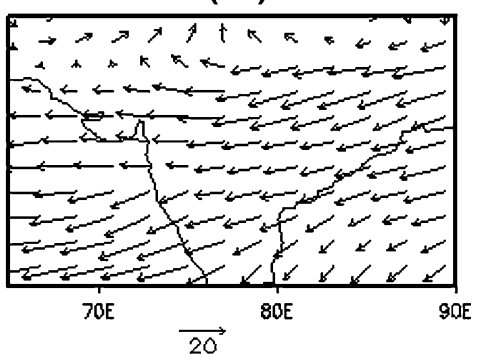

Fig. 13 Wind field (m/s) at $1730 \mathrm{LT}$ (1200 UTC), 26 July, 2005 at $850 \mathrm{hPa}$ (top), $500 \mathrm{hPa}$ (middle), and $200 \mathrm{hPa}$ (bottom), respectively. a1-a3 FNL analysis, b1-b3 member M3 chosen from EXP2 (Fig. 7c) and c1-c3 member M2 chosen from EXP3 (Fig. 10b)

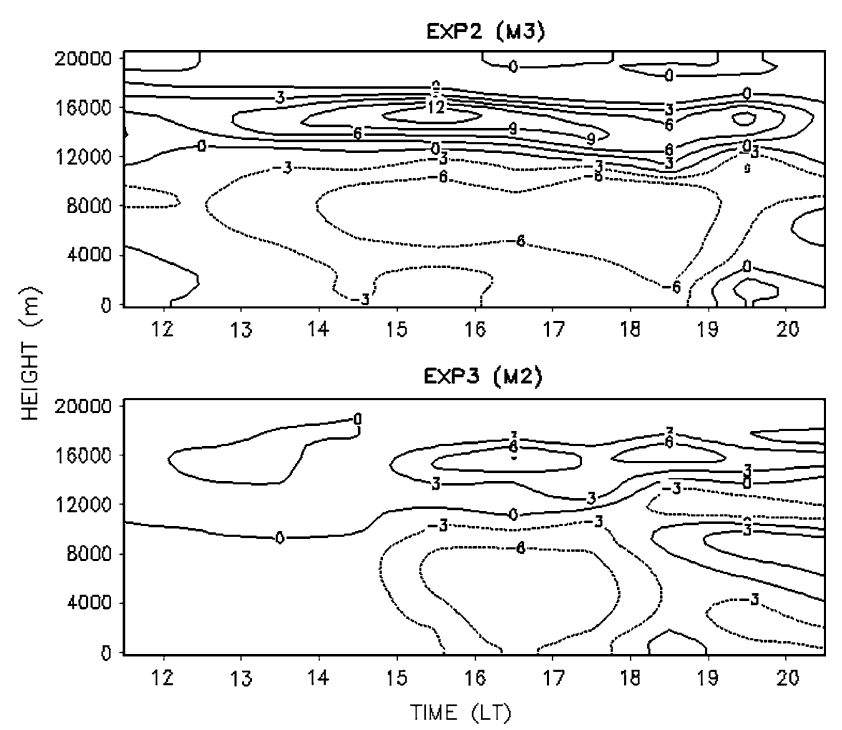

Fig. 14 Time-height section of divergence $\left(10 \mathrm{e}^{-4} / \mathrm{s}\right)$ over an area $(30 \times 30 \mathrm{~km})$ surrounding the location of maximum rainfall, for the member (M3) chosen from EXP2 (top panel), and for the member (M2) chosen from EXP3 (bottom panel)

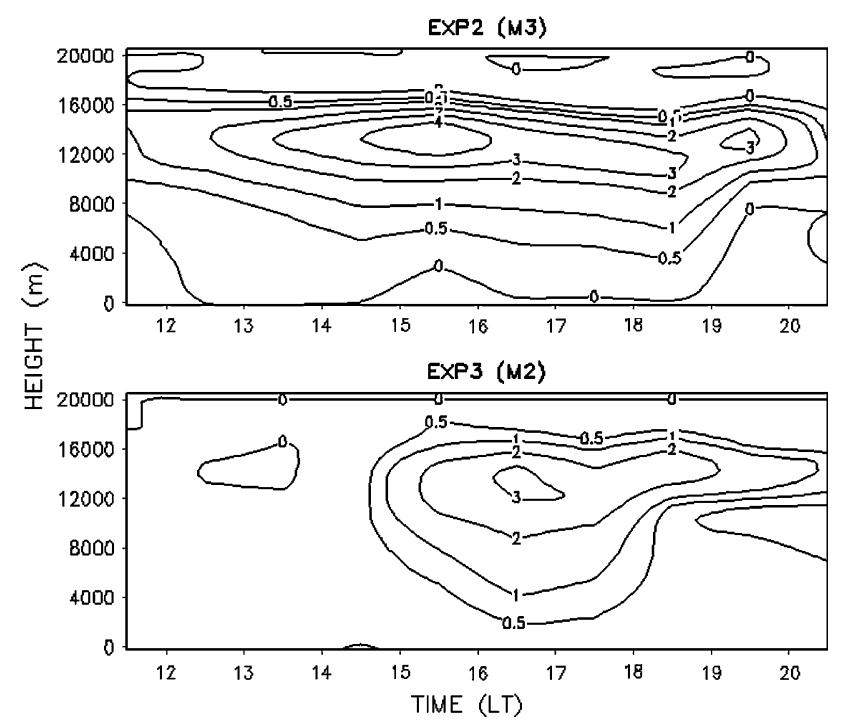

Fig. 15 Same as Fig. 14, but for vertical velocity $(\mathrm{m} / \mathrm{s})$

the initiation of deep convection. Another interesting feature that can be seen from Fig. 16 is that the amount of moisture in the lower troposphere gets reduced temporarily 


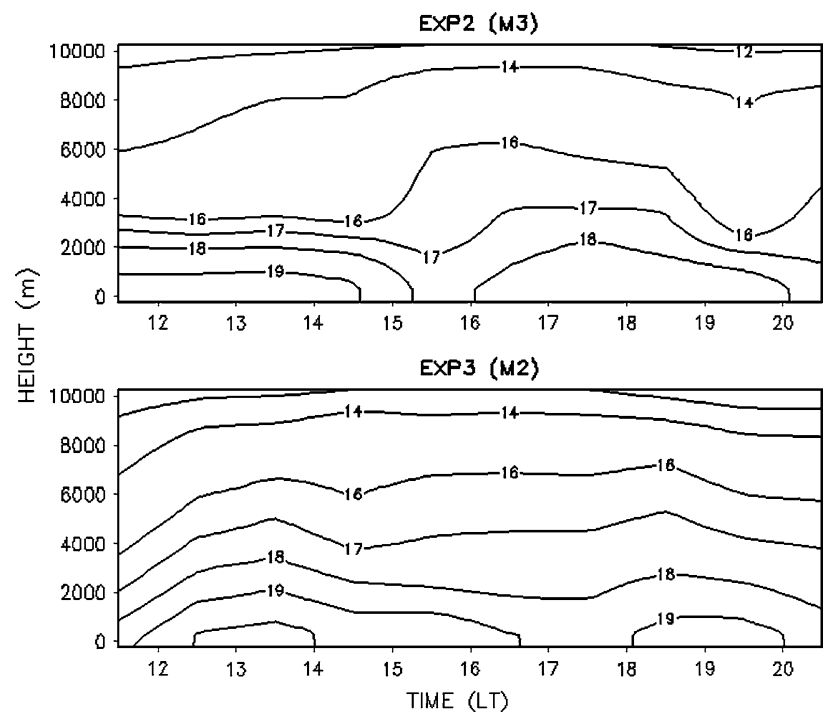

Fig. 16 Same as Fig. 14, but for specific humidity $(\mathrm{g} / \mathrm{kg})$

as a result of rainfall, and then gets enhanced in a short span due to the continuation of moisture convergence. These findings suggest that moisture convergence, rainfall, and its associated latent heat release form a classic case of positive feedback cycle, thus contributing to the overall severity of the event.

Since atmospheric instability is an essential component of deep convection, we next analyze its role in the occurrence of this extreme rainfall event. For this purpose, we use the vertical gradient of equivalent potential temperature as a measure of instability in the atmosphere. A negative vertical gradient of equivalent potential temperature is considered to be an indicator of convective instability. Figure 17 shows that there is a steep decrease of the

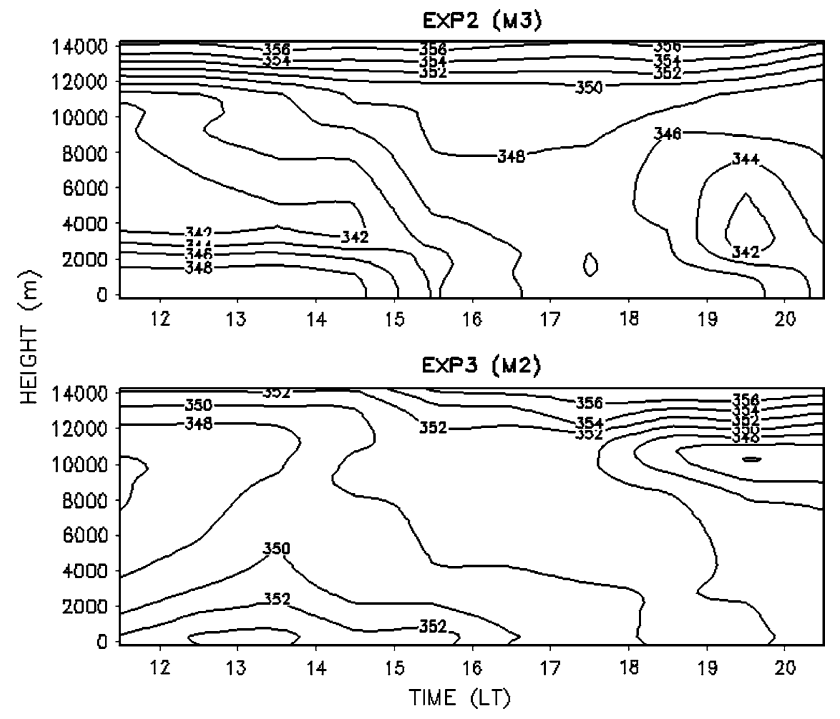

Fig. 17 Same as Fig. 14, but for equivalent potential temperature (K)

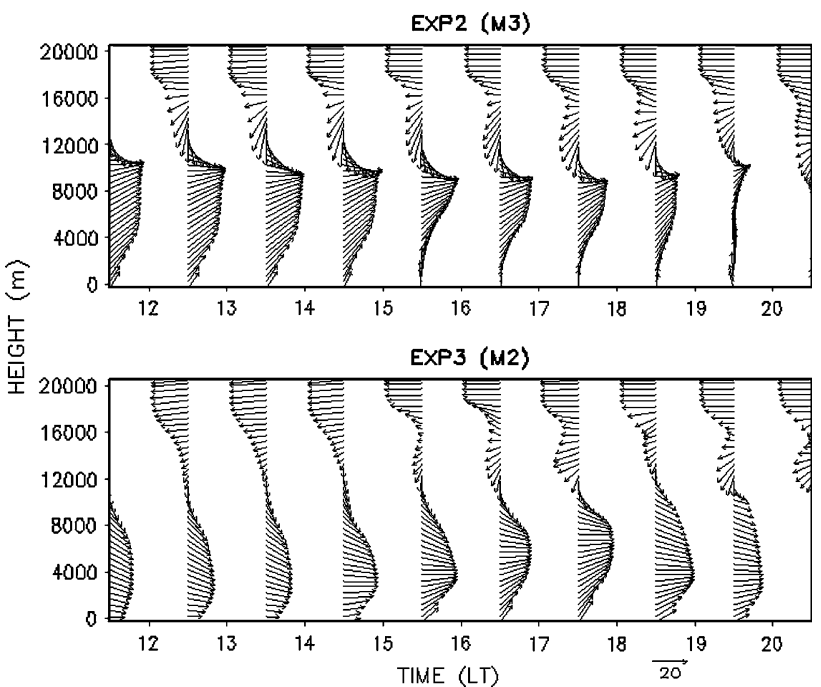

Fig. 18 Same as Fig. 14, but for horizontal wind $(\mathrm{m} / \mathrm{s})$

equivalent potential temperature in the vertical direction, prior to the onset of the event, indicating the presence of strong atmospheric instability.

Some of the past studies have emphasized the role of vertical wind shear in the life cycle of severe thunderstorms (e.g., Doswell et al. 1996). Figure 18 shows that there is a strong vertical wind shear in both simulations. It is also important to note that there is a vertical shear, in magnitude as well as direction of the horizontal wind. A significant increase in the speed with height causes tilting of the updraft, allowing a separation between the regions of updraft and downdraft. This can lead to a further intensification of the storm. On the other hand, directional shear in the lower troposphere initiates development of a rotating updraft, known to play an important role in the genesis of thunderstorms.

Finally, we analyze the vertical profiles of model-simulated hydrometeors in order to contrast the simulated cloud depth with the observed values. Figure 19 shows the evolution of total condensate in the atmosphere, comprising cloud liquid water, rain water, cloud ice, snow and hail, over the region of interest. It can be seen from the figure that the cloud-top heights were around $16-17 \mathrm{~km}$ in both the simulations. Thus, the model-simulated clouds are in very good agreement with the findings of Jenamani et al. (2006), wherein they had reported cloud-top heights of about $17 \mathrm{~km}$ observed near Santacruz, using data obtained from the S-band radar operated by IMD, Mumbai.

\section{Summary}

The purpose of this paper is to evaluate the performance of the ARPS model in simulating the spatio-temporal 


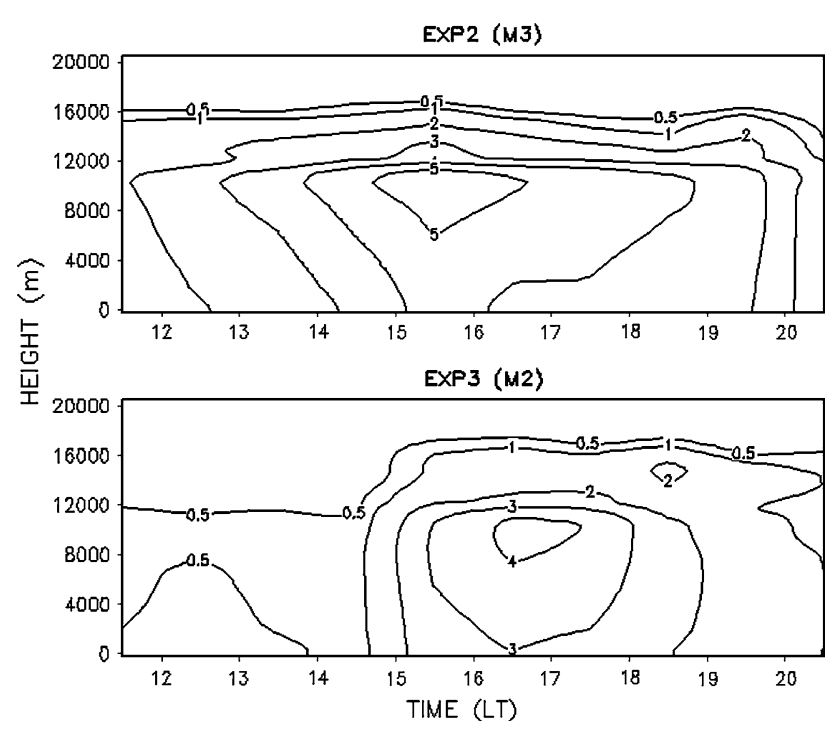

Fig. 19 Same as Fig. 14, but for total condensate ( $\mathrm{g} / \mathrm{kg}$ ), comprising of cloud water, rain water, ice, snow and hail

characteristics of a rainfall event of unprecedented intensity, and subsequently gain insights into the initiation and sustenance of that event. In this regard, three sets of ensemble simulations were conducted using ARPS, with three different experiment setups. The Mumbai rainfall event of 26 July 2005 that led to a record $65 \mathrm{~cm}$ of rainfall accumulation in a span of just $6 \mathrm{~h}$ was chosen as a case study. Three parameters, namely, location, timing, and intensity were chosen to evaluate the model performance.

Even in an idealized framework (with horizontally homogeneous initial conditions) signatures of localized heavy rain were present in the model simulations. For a more detailed analysis, two more sets of ensemble experiments were conducted, one using the standard ensemble technique (EXP2), and the other using SLAF (EXP3) for ensemble construction. It was seen that the time of rainfall peak was well simulated by the model in both sets of ensemble simulations. In addition to the simulated timing of maximum rainfall intensity, it was also found that the model simulations using SLAF were able to simulate the abrupt increase in rainfall intensity that was seen from the observed rainfall time series. The other parameter used for the evaluation of model performance was the intensity of rainfall and the 6-hourly accumulation. In this case the model simulations using SLAF were found to be superior to those using the standard ensemble technique. The location of rainfall peak simulated by the model had spatial shifts (compared to observations) in almost all the simulations. This shift is apparently because of two reasons: (1) deficiency of the moist physics (cumulus scheme and cloud microphysics), and (2) errors present in the initial and boundary conditions used to integrate the model. Furthermore, in regard to the use of convection scheme at higher spatial resolutions, we found from this study that the use of cumulus scheme at finer resolutions of around $6 \mathrm{~km}$ or less appears to simulate a more spatially homogeneous distribution of rainfall.

We also investigated the role of various other diagnostics important in the initiation and sustenance of this particular rain event. To start with, the circulation and thermodynamic features were analyzed by choosing the "best" member from ensemble set of EXP2 and EXP3. From our analysis, it was concluded that all the necessary ingredients needed for a severe thunderstorm were present prior to and during the occurrence of the event. Specifically, there was strong convective instability in the atmosphere, accompanied by high values of specific humidity, and a conducive vertical wind shear. There was a high negative gradient of equivalent potential temperature in the vertical, prior to the onset of the event, thus confirming the presence of strong convective instability present in the atmosphere triggering deep convection. Strong convergence of moist air initiated at the mid-troposphere $(\sim 8 \mathrm{~km})$ and gradually propagated to the lower altitudes. From the analysis of specific humidity, it was seen that a positive feedback cycle formed by the moisture convergence, rainfall and its associated latent heat release added to the severity of the event.

The most striking feature of this thunderstorm was its sustenance for a long period of time, since one would intuitively expect an event of such intensity to be short lived. From the analysis of vertical wind shear, it was found that a strong vertical shear existed, both in magnitude as well as direction of the wind, which was one of the primary reasons leading to the longer lifetime of the thunderstorm. The vertical profile of hydrometeors revealed that the model-simulated cloud-top heights were around 16-17 km and in very good agreement with the observed value $(\sim 17 \mathrm{~km})$ over the location of maximum rainfall.

Acknowledgments The authors would like to thank Fanyou Kong of the Center for Analysis and Prediction of Storms, University of Oklahoma and S.S. Vaidya of the Indian Institute of Tropical Meteorology for their useful suggestions and help during the course of this work. The use of Advanced Regional Prediction System (ARPS) developed by the Center for Analysis and Prediction of Storms, University of Oklahoma, and rainfall data from the India Meteorological Department is thankfully acknowledged. Finally, we would like to thank the two anonymous reviewers for their useful suggestions which helped improve the manuscript.

Open Access This article is distributed under the terms of the Creative Commons Attribution Noncommercial License which permits any noncommercial use, distribution, and reproduction in any medium, provided the original author(s) and source are credited.

\section{References}

Adler RF, Huffman GJ, Bolvin DT, Curtis S, Nelkin EJ (2000) Tropical rainfall distributions determined using TRMM 
combined with other satellite and rain gauge information. J Appl Meteorol 39:2007-2023

Benson CR, Rao GV (1987) Convective bands as structural components of an Arabian Sea convective cloud cluster. Mon Wea Rev 115:3013-3023

Chakraborty A, Mujumdar M, Behera SK, Ohba R, Yamagata T (2006) A cyclone over Saudi Arabia on 5 January 2002: a case study. Meteorol Atmos Phys 93:155-122

Deb SK, Kishtawal CM, Pal PK, Joshi PC (2008) Impact of TMI SST on the simulation of a heavy rainfall episode over Mumbai on 26 July 2005. Mon Wea Rev 136:3714-3741

Dhar ON, Nandargi SS (1998) Rainfall magnitudes that have not exceeded in India. Weather 53:145-151

Doswell CA III, Brooks HE, Maddox RA (1996) Flash flood forecasting: an ingredients-based methodology. Weather Forecast 11:560-581

Droegemeier, KK, Bassett G, Xue M (1994) Very high-resolution, uniform-grid simulations of deep convection on a massively parallel processor: Implications for small-scale predictability. Preprints, 10th Conference on Numerical Weather Prediction, Portland, OR, Am Meteor Soc, 376-379

Huffman GJ, Adler RF, Bolvin DT, Gu G, Nelkin EJ, Bowman KP, Hong Y, Stocker EF, Wolff DB (2007) The TRMM Multisatellite Precipitation Analysis (TMPA): Quasi-global, multiyear, combined-sensor precipitation estimates at fine scales. J Hydrometeorol 8:38-55. doi:10.1175/JHM560.1

Jenamani RK, Bhan SC, Kalsi SR (2006) Observational/forecasting aspects of the meteorological event that caused a record highest rainfall in Mumbai. Curr Sci 90:1344-1362

Kalnay E (2003) Atmospheric Modeling, Data Assimilation and Predictability. Cambridge Press, Cambridge $341 \mathrm{pp}$

Kong F, Droegemeier KK, Venugopal V, Foufoula-Georgiou E (2004) Application of scale-recursive estimation to ensemble forecasts: a comparison of coarse and fine resolution simulations of a deep convective storm. 20th conference on weather analysis and forecasting and 16th conference on numerical weather predication, Seattle, WA, Am Meteor Soc (Preprint)

Kong F, Droegemeier KK, Hickmon NL (2006) Multi-resolution ensemble forecasts of an observed tornadic thunderstorm system.
Part I: comparison of coarse- and fine-grid experiments. Mon Weather Rev 134:807-833

Krishnamurti TN, Hawkins RS (1970) Mid-tropospheric cyclones of the southwest monsoon. J Appl Meteor 9:442-458

Kulkarni AK, Mandal BN, Sangam RB (1998) Some facts about heavy rainfall distribution over the Konkan region. Proc Workshop on Scientific Aspects of Water Management, April 1998, 12-21

Kumar A, Dudhia J, Rotunno R, Niyogi D, Mohanty UC (2008) Analysis of the 26 July 2005 heavy rain event over Mumbai, India using the Weather Research and Forecasting (WRF) model. Q J R Meteorol Soc 134:1897-1910

Mishra SK, Srinivasan J, Nanjundiah RS (2008) The impact of time step on the intensity of ITCZ in aqua-planet GCM. Mon Weather Rev 136:4077-4091

Ogura Y, Yoshizaki M (1988) Numerical study of orographicconvective precipitation over the eastern Arabian Sea and the Ghat Mountains in the summer monsoon season. J Atmos Sci 45:2097-2122

Romero R, Ramis C, Alonso S, Doswell CA, Stensrud DJ (1998) Mesoscale model simulations of three heavy precipitation events in the western Mediterranean region. Mon Weather Rev 126:1859-1881

Vaidya SS, Kulkarni JR (2007) Simulation of heavy precipitation over Santacruz, Mumbai on 26 July 2005, using Mesoscale model. Meteorol Atmos Phys 98:55-66

Weisman ML, Skamarock WC, Klemp JB (1997) The resolution dependence of explicitly modeled convective systems. Mon Weather Rev 125:527-548

Xue M, Droegemeier KK, Wong V (2000) The advanced regional prediction system (ARPS) - a multi-scale non-hydrostatic atmospheric simulation and prediction model. Part I: Model dynamics and verification. Meteorol Atmos Phys 75:161-193

Xue M, Droegemeier KK, Wong V, Shapiro A, Brewster K, Carr F, Weber D, Liu Y, Wang D (2001) The advanced regional prediction system (ARPS) - a multiscale non-hydrostatic atmospheric simulation and prediction tool. Part II: Model physics and application. Meteorol Atmos Phys 76:143-165 